\title{
ISOLATION AND CHARACTERIZATION OF SOME ENTEROBACTERIACEAE ISOLATED FROM EARLY MORTALITIES IN JAPANESE QUAIL CHICKS AT QENA GOVERNORATE, EGYPT
}

\author{
WALEED YOUNIS $^{1}$; MAHMOUD SABRA ${ }^{2}$, EHAB KOTB ELMAHALLAWY ${ }^{3}$ AND \\ HAITHAM HELMY SAYED ${ }^{4}$ \\ ${ }^{1}$ Department of Microbiology, Faculty of Veterinary Medicine, South Valley University, Qena, 83523 Egypt. \\ ${ }^{2}$ Department of Poultry Diseases, Faculty of Veterinary Medicine, South Valley University, Qena, 83523 Egypt. \\ ${ }^{3}$ Department of Zoonoses, Faculty of Veterinary Medicine, Sohag University, Sohag, 82524, Egypt. \\ ${ }^{4}$ Department of Microbiology, Faculty of Veterinary Medicine, Sohag University, Sohag, 82524, Egypt.
}

Received: 2 August 2021; Accepted: 30 August 2021

\begin{abstract}
Quail farms become widely spread in Egypt as a source of meat. Early mortality of quail chicks is one of quail breeding limiting factors. This study was performed to study role of some Enterobacteriaceae as a parable cause of early mortality in South Valley University quail farm, characterize isolates phenotypically and serologically, determine their antimicrobial sensitivity and to screen all isolates for presence of florfenicol resistance gene (floR), Quaternary ammonium compounds resistance gene $(Q a c A / B)$ and class 1 integrons gene (Int 1) and to screen E. coli, Salmonella and $K$. pneumoniae isolates for intimin encoding gene (eaeA), invasive encoding gene (invA) and mucoviscosity associated gene (magA) respectively. Therefore, 80 freshly dead or moribund Japanese quail chicks under 12 days of age were collected from this farm during the period from December 2020 to April 2021 for clinical assessment and bacterial isolation. Totally, $14 \mathrm{E}$. coli, 6 Salmonella and $1 \mathrm{~K}$. pneumoniae isolates were isolated and phenotypically identified from the internal organs of the examined quail chicks with percentage of $(17.5 \%),(7.5 \%)$ and $(1.25 \%)$ respectively. $E$. coli isolates belonged to 5 different $\mathrm{O}$-serogroups comprising $\mathrm{O}_{86}(28.6 \%), \mathrm{O}_{78}(21.4 \%), \mathrm{O}_{26}$ (14.3\%), $\mathrm{O}_{55}(14.3 \%)$ and $\mathrm{O}_{164}(7.1 \%)$ in addition to 2 nontypeable isolates (14.3\%) while all Salmonella isolates were serologically identified as S. Typhimurium with antigenic formula 1,4,[5],12:i:1,2. All isolates were weak biofilm producer except (33.3\%) of S. Typhimurium isolates and showed Congo red binding activity except (28.6\%) of E. coli isolates while only $(14.3 \%)$ of $E$. coli isolates had hemolytic activity. Antimicrobial susceptibility testing for the isolates to 10 different antibiotics revealed that all the isolates were sensitive only to chloramphenicol and oxytetracycline except $(42.9 \%)$ and $(85.7 \%)$ of E. coli isolates respectively and to azithromycin except $(35.7 \%)$ of $E$. coli isolates and $K$. pneumoniae. PCR revealed that all the isolates harbor Int1 and floR genes, $(100 \%)$ and $(33.3 \%)$ of $S$. Typhimurium isolates harbor $i n v A$ and $Q a c A / B$ genes respectively and only (21.4\%) of E. coli isolates harbor $e a e A$ and $Q a c A / B$ genes. It was concluded that E. coli and $S$. Typhimurium are a major cause of early mortality of Japanese quail chicks.
\end{abstract}

Keywords: Enterobacteriaceae, mortalities, Japanese quail, Qena Governorate, Egypt.

Corresponding author: HAITHAM HELMY SAYED

E-mail address: vet_haitham@yahoo.com

Present address:Department of Microbiology, Faculty of Veterinary Medicine, Sohag University, Sohag, 82524, Egypt. 


\section{INTRODUCTION}

Poultry industry is considered an important sector to meet the great demands of animal protein all over the world (Abd ElGhany, 2019). Rearing of birds other than chickens as quails has been developed in the recent years worldwide to supply the human food requirements (Khoshbakht et al., 2017). Quails represent a hopeful source to cover the animal protein deficiency in the developing countries including Egypt (Farghaly et al., 2017).

Quails farming is increasing globally day by day as it requires low rearing investment and has fast financial returns. Moreover, quails is characterized by low feed intake, rapid growth rate, early sexual maturity, short generation interval, short incubation period, high nutritional value of meat, and less susceptibility to the infectious diseases compared to the other poultry species (Santos et al., 2011; Yusuf et al., 2016 and Hassan et al., 2017).

Egypt has fast-growing quail industry (Da Cunha, 2009). Nowadays, quails become widely distributed in Egypt as a source of meat production, since their meat has become highly popular among the Egyptian consumers (Mosaad et al., 2000).

The advancement in quail production is being obstructed by some managemental factors, infectious and non-infectious diseases (Barnes and Gross, 1997). Early mortality of quail chicks is one of the limiting factors in breeding of quails. Bacterial infection is one of the most important causes of quail chick's early mortality where various causative microorganisms are transmitted through the yolk sac. Salmonella and E. coli are the most important factors in yolk sac infection, other bacteria as Proteus and Bacillus can also cause yolk sac infection. Furthermor, E. coli bacteria are common in eggshell contamination. Poor management in breeder farm and hatchery hygiene are some of the predisposing factors to quail chick's early mortality (Boroomand et al., 2018).
E. coli and Salmonella are considered of the main causes of morbidity and mortality in poultry industry worldwide and they cause huge economic losses. E. coli causes different disease manifestations in poultry including omphalitis, septicemia, respiratory tract infection, enteritis, coli granuloma, swollen head syndrome, cellulitis, polyserositis, and salpingitis. On the other hand, Salmonella serotypes cause different acute and chronic diseases in poultry (Kabir, 2010).

There is a wide variation in Salmonella serovars commonly infecting poultry and the serovars may vary geographically (ElDemerdash et al., 2013). It is also known that a lot of Salmonella serotypes affect human, but some are more pathogenic for human (Hendriksen et al., 2011). Avian pathogenic E. coli (APEC) are very various, which are associated to the virulence factors and serotypes of them (Mellata et al., 2009). Antimicrobial resistance-associated and virulence-associated genes are responsible for the virulence potential of pathogenic bacteria (Capuano et al., 2013).

Quail play a significant role in spreading of many pathogens which have public health significance (Mosaad et al., 2000). E. coli and Salmonella are the most avian pathogens that cause food borne illnesses in most countries of the world (Kabir, 2010). It is widely accepted that design of any program for prevention of food borne diseases and/or spreading of the pathogens to the environment should be started from the farm (Farghaly et al., 2017). Disinfectants are important components of the biosecurity programs. QACs are vigorous detergents widely used in poultry farms and it is the disinfectant of choice for disinfection of the equipment as incubators and hatching trays (Haynes and Smith, 2003). Genes of QAC resistance are extremely existed among $E$. coli isolates and they were extremely associated with antimicrobial resistant isolates (Ibrahim et al., 2019).

Antimicrobial resistance is an increasingly significant problem in human and animals 
(Jahantigh et al., 2013). The excessive use of antibiotics in the intensive animals production especially poultry and pork represent the cornerstone for emergence, permanence and spreading of the resistant bacteria (WHO, 2014). Development of multidrug resistant (MDR) pathogens makes prevention and control of the bacterial diseases of great difficulty affecting not only poultry industry but also human through transmission of such pathogens via consumption of the contaminated products (Darwish et al., 2013).

Resistance genes acquisition particularly by the mobile genetic elements is considered the main factor in the wide spreading of the antimicrobial resistance (Odumosu et al., 2013). Antibiotic resistance gene cassettes found most in association with class 1 or class 2 integrons (Dawes et al., 2010). Capture and spreading of the antibiotic resistance genes via integrons stimulate the rapid evolution of multidrug resistances among Gram-negative bacteria (Rowe-Magnus et al., 2002).

There are limited researches about the early mortality in the Egyptian quail farms, role of some Enterobacteriaceae members as a probable cause of this problem and about the antibiotic resistance of Enterobacteriaceae members isolated from quails. Appropriate knowledge about the diseases affecting quails is necessary for the suitable control and preventive programs in quail production. Furthermore, studying prevalence of the zoonotic microorganisms which are transmitted to human through foods of animal origin and their antibiotic resistance represent a major concern for public health. Therefore, the present study aimed to investigate role of some Enterobacteriaceae members as a probable cause of early mortality in South Valley University quail farm, characterize the isolates phenotypically and serologically, determine their antimicrobial sensitivity and to screen them for presence of some virulence genes, antibiotic and disinfectant resistance genes in addition to Intl gene.

\section{MATERIALS AND METHODS}

\section{1- Sampling and clinical examination:}

During the period from December 2020 to April 2021, 80 freshly dead and moribund Japanese quail chicks under 12 days of age from South Valley University quail farm were received at Department of Poultry Diseases, Faculty of Veterinary Medicine, South Valley University, Egypt for clinical assessment and diagnosis. Moribund quail chicks were killed humanely by neck dislocation. The collected quail chicks' were subjected to clinical, post mortem and bacteriological examinations. Under aseptic conditions, samples were collected from liver, spleen, kidney, yolk sac, lung and heart.

\section{2- Bacterial isolation and biochemical identification:}

The samples were inoculated into tryptone soya broth (TSB) (Oxoid, England) and incubated under aerobic condition at $37^{\circ} \mathrm{C}$ for $24 \mathrm{hrs}$. then streaked onto MacConkey agar (Oxoid, England) and incubated at $37^{\circ} \mathrm{C}$ for $24 \mathrm{hrs}$. The pink colonies were sub-cultured on eosin methylene blue (EMB) agar (Oxoid, England) and the pale colonies were sub-cultured on Xylose Lysine Deoxycholate (XLD) media (Oxoid, England). The isolates were preserved at $-80^{\circ} \mathrm{C}$ in TSB (Oxoid, England) supplemented with $15 \%$ glycerol till the further identification. The suspected isolates were identified through assessment of their morphological characteristics, Gram-staining, catalase and oxidase test using the standard laboratory methods described by Holt et al. (1994) and API 20E system (bioMerieux, France) according to the manufacturer's instructions. The isolates were identified as $E$. coli, Salmonella and K. pneumoniae according to criteria of Mahon and Lehman (2019).

\section{3 - Serotyping of E. coli and Salmonella isolates:}

Serotyping of E. coli and Salmonella isolates was carried out by slide agglutination test using diagnostic polyvalent and monovalent $E$. coli antisera and diagnostic $\mathrm{O}$ and $\mathrm{H}$ Salmonella antisera obtained from Sifin diagnostics $\mathrm{GmbH}$, 
Germany. E. coli isolates were serotyped according to Edwards and Ewing (1972) while Salmonella isolates were serologically identified following Kauffman-White Scheme (Grimont and Weill, 2007).

\section{4- Determination some virulence factors of the isolates:}

\section{1- Biofilm formation by Microtiter plate (MTP) assay:}

The ability of bacterial isolates to form biofilm was assessed by microtiter plate method according to Melo et al. (2013) with slight modification. Briefly, overnight cultures of the tested strains were diluted by 1: 100 in trypticase soy broth contain $0.5 \%$ glucose. $200 \mu 1$ of the formerly prepared suspensions were added to the wells of a polystyrene plate (Costar, New York, USA). Each strain was tested in triplicate and three wells were used as a negative control (contained $200 \mu \mathrm{l}$ of $\mathrm{TSB}+0.5 \%$ glucose only). After 24hrs. of incubation at $37^{\circ} \mathrm{C}$, bacterial suspension was removed and washed by phosphate buffer saline three times then staining with crystal violet $(0.1 \%)$ was done for all wells for $15 \mathrm{~min}$, after that the dye was removed, the biofilm-bound dye was then eluted with $95 \%$ ethanol, The optical densities (OD) of the stained adherent films were determined with microplate reader (BioTek ELX800, USA) at $620 \mathrm{~nm}$. Results were interpreted according to (Stepanović et al., 2007).

\section{2- Congo red binding assay:}

Bacterial isolates were grown at $37^{\circ} \mathrm{C}$ for 24 hrs. on tryptic soy agar (Oxoid, UK) supplemented with $0.02 \%$ Congo red (Sigma, USA) and $0.15 \%$ bile salt (Difico, USA). The isolates that produced red colonies were recorded as Congo red positive while those that produced grayish-white colonies were recorded as Congo red negative according (Roy et al., 2006).

\section{3- Hemolytic activity:}

Overnight bacterial cultures of the isolates were streaked on blood agar base (Oxoid, UK) containing $10 \%$ citrated sheep blood and then incubated at $37^{\circ} \mathrm{C}$ for $24 \mathrm{hrs}$. Hemolysis is indicated by appearance of erythrocytes lysis according to (Roy et al., 2006).

\section{5- Antimicrobial Susceptibility Testing:}

The antimicrobial susceptibility of the isolates was determined by Kirby-Bauer disc diffusion method using the antibiotics disks (HiMedia, India) illustrated in Table (1). Each isolate was streaked onto Mueller-Hinton agar (Oxoid, UK), antibiotic disks were dispensed and the inoculated plate was incubated at $37^{\circ} \mathrm{C}$ for 24 hrs. Inhibition zones diameters were measured and interpreted according to the CLSI (2006). Resistant to more than 3 antibiotics was considered as MDR (Magiorakos et al., 2012).

Table 1: Antibiotics used in antimicrobial susceptibility testing with discs concentration.

\begin{tabular}{cccc}
\hline Antibiotic & $\begin{array}{c}\text { Disc } \\
\text { concentration }\end{array}$ & Antibiotic & $\begin{array}{c}\text { Disc } \\
\text { concentration }\end{array}$ \\
\hline Ampicillin (AMP) & $30 \mu \mathrm{g}$ & $\begin{array}{c}\text { Amoxicillin/clavulanic acid } \\
\text { (AMC) }\end{array}$ & $30 \mu \mathrm{g}$ \\
\hline Cefazolin (CZ) & $30 \mu \mathrm{g}$ & Cefotaxime (CTX) & $30 \mu \mathrm{g}$ \\
\hline Kanamycin (K) & $30 \mu \mathrm{g}$ & Azithromycin (AZM) & $15 \mu \mathrm{g}$ \\
\hline Clindamycin (DA) & $2 \mu \mathrm{g}$ & Oxytetracycline (T) & $30 \mu \mathrm{g}$ \\
\hline Chloramphenicol $(\mathrm{C})$ & $30 \mu \mathrm{g}$ & Nitrofurantoin $(\mathrm{F})$ & $300 \mu \mathrm{g}$ \\
\hline
\end{tabular}

6 - Detection of some genes in the isolates by PCR:

In this study, all the isolates were screened by the conventional PCR for presence of floR, $Q a c A / B$ and Intl genes. Furthermore, E. coli, $S$.
Typhimurium and $K$. pneumoniae isolates were screened for presence of $e a e A$, invA and magA genes respectively. The used oligonucleotide primers are illustrated in Table (2) and they were obained from Metabion (Germany). 


\section{1-DNA extraction:}

Total bacterial DNA was extracted from an overnight subculture on TSB using GeneJET Genomic DNA Purification kit (Thermo Fisher Scientific, Baltics UAB, Lithuania) according to the manufacturer's instructions. Concentration of the extracted DNA from each isolate was measured by Nano Drop ${ }^{\mathrm{TM}}$ Lite spectrometer (Thermo scientific, Germany) then it was preserved at $-20^{\circ} \mathrm{C}$ till be used.

\section{2-PCR amplification:}

DNA was amplified using Emerald Amp Max PCR Master Mix (Takara, Japan) in a thermocycler (Applied biosystem 2720, USA) and under PCR conditions illustrated for each target gene in Table (2). According to manufacturer's instructions of mastermix, the reaction mixture was prepared in $25 \mu \mathrm{l}$ containing $12.5 \mu \mathrm{l}$ of Master Mix, $1 \mu \mathrm{l}$ from each of forward and reverse primers, $5 \mu$ from extracted DNA and $5.5 \mu \mathrm{l}$ of nuclease-free water.

\section{3-Analysis of the PCR products:}

Products of PCR were electrophoresed on 1\% agarose gel (Applichem $\mathrm{GmbH}$, Germany) in $1 \mathrm{x}$ TBE buffer at room temperature using gradients of $5 \mathrm{~V} / \mathrm{cm}$. To determine the fragment sizes, Generuler 100 bp DNA ladder (Thermo scientific, Germany) was used. Then, the gel was photographed by a gel documentation system (Alpha Innotech, Biometra).

Table 2: The target genes in the study, oligonucleotide primers and PCR conditions used.

\begin{tabular}{|c|c|c|c|c|c|c|c|c|}
\hline \multirow{2}{*}{$\begin{array}{l}\text { Target } \\
\text { gene }\end{array}$} & \multirow{2}{*}{$\begin{array}{l}\text { Primers sequences } \\
\qquad\left(5^{\circ}-3^{`}\right)\end{array}$} & \multirow{2}{*}{$\begin{array}{l}\text { Product } \\
\text { Size (bp) }\end{array}$} & \multirow{2}{*}{$\begin{array}{c}\text { Primary } \\
\text { denaturation }\end{array}$} & \multicolumn{3}{|c|}{ PCR conditions ( 35 cycles) } & \multirow{2}{*}{$\begin{array}{c}\text { Final } \\
\text { extension }\end{array}$} & \multirow{2}{*}{ Reference } \\
\hline & & & & Denaturation & Annealing & Extension & & \\
\hline $\begin{array}{c}\text { invA of } \\
\text { Salmonella }\end{array}$ & $\begin{array}{c}\text { GTGAAATTAT } \\
\text { CGCCACGTTC } \\
\text { GGGCAA } \\
\text { TCATCGCACC } \\
\text { GTCAAAGGAA } \\
\text { CC }\end{array}$ & 284 & $\begin{array}{l}94^{\circ} \mathrm{C} \\
5 \mathrm{~min} .\end{array}$ & $\begin{array}{l}94^{\circ} \mathrm{C} \\
30 \mathrm{sec} .\end{array}$ & $\begin{array}{c}55^{\circ} \mathrm{C} \\
40 \mathrm{sec} .\end{array}$ & $\begin{array}{l}72^{\circ} \mathrm{C} \\
45 \mathrm{sec}\end{array}$ & $\begin{array}{l}72^{\circ} \mathrm{C} \\
7 \mathrm{~min} .\end{array}$ & $\begin{array}{l}\text { Oliveira } e t \\
\text { al. }(2003)\end{array}$ \\
\hline $\begin{array}{l}\text { eaeA of } \\
\text { E. coli }\end{array}$ & $\begin{array}{c}\text { ATGCTTAGTGC } \\
\text { TGGTTTAGG } \\
\text { GCCTTCATCAT } \\
\text { TTCGCTTTC } \\
\end{array}$ & 248 & $\begin{array}{l}95^{\circ} \mathrm{C} \\
3 \mathrm{~min}\end{array}$ & $\begin{array}{c}95^{\circ} \mathrm{C} \\
30 \mathrm{sec} .\end{array}$ & $\begin{array}{l}55^{\circ} \mathrm{C} \\
30 \mathrm{sec} .\end{array}$ & $\begin{array}{l}72^{\circ} \mathrm{C} \\
72 \mathrm{sec}\end{array}$ & $\begin{array}{l}72^{\circ} \mathrm{C} \\
7 \mathrm{~min} .\end{array}$ & $\begin{array}{c}\text { Bisi- } \\
\text { Johnson } \text { et } \\
\text { al. }(2011)\end{array}$ \\
\hline $\begin{array}{l}\text { magA of } \\
\text { Klebsiella }\end{array}$ & $\begin{array}{c}\text { GGTGCTCTTTA } \\
\text { CATCATTGC } \\
\text { GCAATGGCCA } \\
\text { TTTGCGTTAG } \\
\end{array}$ & 1282 & $\begin{array}{l}94^{\circ} \mathrm{C} \\
5 \mathrm{~min} .\end{array}$ & $\begin{array}{l}94^{\circ} \mathrm{C} \\
45 \mathrm{sec} .\end{array}$ & $\begin{array}{l}55^{\circ} \mathrm{C} \\
60 \mathrm{sec} .\end{array}$ & $\begin{array}{l}72^{\circ} \mathrm{C} \\
72 \mathrm{sec}\end{array}$ & $\begin{array}{l}72^{\circ} \mathrm{C} \\
7 \mathrm{~min}\end{array}$ & $\begin{array}{l}\text { Yeh et al. } \\
\quad(2007)\end{array}$ \\
\hline floR & $\begin{array}{c}\text { TTTGGWCCGC } \\
\text { TMTCRGAC } \\
\text { SGAGAARAAG } \\
\text { ACGAAGAAG }\end{array}$ & 494 & $\begin{array}{l}94^{\circ} \mathrm{C} \\
5 \mathrm{~min}\end{array}$ & $\begin{array}{l}94^{\circ} \mathrm{C} \\
30 \mathrm{sec} .\end{array}$ & $\begin{array}{l}50^{\circ} \mathrm{C} \\
40 \mathrm{sec} .\end{array}$ & $\begin{array}{l}72^{\circ} \mathrm{C} \\
45 \mathrm{sec}\end{array}$ & $\begin{array}{l}72^{\circ} \mathrm{C} \\
10 \mathrm{~min}\end{array}$ & $\begin{array}{l}\text { Doublet } e t \\
\text { al. (2003) }\end{array}$ \\
\hline$Q a c A / B$ & $\begin{array}{c}\text { GCAGAAAGTG } \\
\text { CAGAGTTCG } \\
\text { CCAGTCCAAT } \\
\text { CATGCCTG } \\
\end{array}$ & 361 & $\begin{array}{l}94^{\circ} \mathrm{C} \\
5 \mathrm{~min} .\end{array}$ & $\begin{array}{l}94^{\circ} \mathrm{C} \\
30 \mathrm{sec} .\end{array}$ & $\begin{array}{l}53^{\circ} \mathrm{C} \\
40 \mathrm{sec} .\end{array}$ & $\begin{array}{l}72^{\circ} \mathrm{C} \\
40 \mathrm{sec}\end{array}$ & $\begin{array}{l}72^{\circ} \mathrm{C} \\
7 \mathrm{~min}\end{array}$ & $\begin{array}{l}\text { Noguchi } e t \\
\text { al. (2005) }\end{array}$ \\
\hline Int 1 & $\begin{array}{c}\text { CCTCCCGCAC } \\
\text { GATGATC } \\
\text { TCCACGCATC } \\
\text { GTCAGGC }\end{array}$ & 280 & $\begin{array}{l}94^{\circ} \mathrm{C} \\
10 \mathrm{~min} .\end{array}$ & $\begin{array}{l}94^{\circ} \mathrm{C} \\
60 \mathrm{sec} .\end{array}$ & $\begin{array}{l}54^{\circ} \mathrm{C} \\
60 \mathrm{sec} .\end{array}$ & $\begin{array}{l}72^{\circ} \mathrm{C} \\
2 \mathrm{~min} .\end{array}$ & $\begin{array}{l}72^{\circ} \mathrm{C} \\
10 \mathrm{~min}\end{array}$ & $\begin{array}{l}\text { Zhao et al. } \\
\quad(2001)\end{array}$ \\
\hline
\end{tabular}




\section{RESULTS}

\section{1- Results of clinical and post-mortem examination:}

Clinically, the affected quail chicks showed depression, huddling together, ruffling feathers, some showed pasty vent. At necropsy, general congestion in internal organs (lung, liver, spleen and intestine), unabsorbed yolk sac, some showed inflammation in the pericardium and air sacs, typhlitis, urolithiasis and distension of ureters with urate.

2- Results of bacterial isolation and phenotypic identification:

Based on the morphological and biochemical characteristics of the isolates, $14 \mathrm{E}$. coli isolates (E1-E14), 6 Salmonella isolates (S1-S6) and 1 $K$. pneumoniae isolate were isolated and identified phenotypically from liver, spleen, kidney, yolk sac, lung and heart of the examined quail chicks with percentage of $(17.5 \%),(7.5 \%)$ and $(1.25 \%)$ respectively.

E. coli isolates produced pink colonies on MacConkey agar and dark colonies with green metallic sheen on EMB agar and they were oxidase negative, catalase positive, indole positive, methyl red (MR) positive, VogesProskauer (VP) negative and negative in citrate utilization test. $K$. pneumoniae isolate produced pink mucoid colonies on MacConkey agar and pink mucoid colonies on EMB and it was oxidase negative, catalase positive, indole negative, MR negative, VP positive and positive in citrate utilization test. While, Salmonella isolates produced pale colonies on MacConkey agar and pink colonies with dark center on XLD agar and they were oxidase negative, catalase positive, indole negative, MR positive, VP negative, negative in citrate utilization test and produced $\mathrm{H}_{2} \mathrm{~S}$.

3- Results of serotyping of $E$. coli and Salmonella isolates:

Serotyping demonstrated that E. coli isolates belonged to 5 different O-serogroups comprising $\mathrm{O}_{86}, \mathrm{O}_{78}, \mathrm{O}_{26}, \mathrm{O}_{55}$ and $\mathrm{O}_{164}$ in addition to 2 nontypeable isolates as illustrated in Table (3) while all Salmonella isolates were serologically identified as $S$. Typhimurium with the antigenic formula 1,4,[5],12:i:1,2.

Table 3: O-Serogroups of E. coli isolates.

\begin{tabular}{ccccccc}
\hline O-Serogroup & $\mathrm{O}_{86}$ & $\mathrm{O}_{78}$ & $\mathrm{O}_{26}$ & $\mathrm{O}_{55}$ & $\mathrm{O}_{164}$ & Nontypeable \\
\hline $\begin{array}{c}\text { Number of } \\
\text { isolates }\end{array}$ & 4 & 3 & 2 & 2 & 1 & 2 \\
\hline$\%$ & $28.6 \%$ & $21.4 \%$ & $14.3 \%$ & $14.3 \%$ & $7.1 \%$ & $14.3 \%$ \\
\hline $\begin{array}{c}\text { Isolates belonged } \\
\text { to this Serogroup }\end{array}$ & $\begin{array}{c}\mathrm{E} 8, \mathrm{E} 12 \text { and E13 } \\
\text { E }\end{array}$ & $\begin{array}{c}\mathrm{E} 2, \mathrm{E} 7 \\
\text { and E11 }\end{array}$ & $\mathrm{E} 5$ and E9 & $\mathrm{E} 1$ and E4 & E14 & E3 and E6 \\
\hline
\end{tabular}

\section{4- Results of determination some virulence} factors of the isolates:

It was found that all E. coli isolates were weak biofilm producer, (71.4\%) of them showed Congo red binding activity and only (14.3\%) of them had hemolytic activity (Table 4). On the other hand, All S. Typhimurium isolates showed
Congo red binding activity while hadn't hemolytic activity and (66.7\%) of them were weak biofilm producer (S1 and S5 weren't biofilm producer). K. pneumoniae isolate was weak biofilm producer, showed Congo red binding activity but hadn't hemolytic activity. 
Table 4: Some virulence factors of $E$. coli isolates.

\begin{tabular}{ccccc}
\hline E. coli isolate & O-Serogroup & Biofilm formation & Congo red binding activity & Hemolytic activity \\
\hline E1 & $\mathrm{O}_{55}$ & Weak producer & + & - \\
\hline E2 & $\mathrm{O}_{78}$ & Weak producer & + & - \\
\hline E3 & Nontypeable & Weak producer & - & + \\
\hline E4 & $\mathrm{O}_{55}$ & Weak producer & + & - \\
\hline E5 & $\mathrm{O}_{26}$ & Weak producer & + & - \\
\hline E6 & Nontypeable & Weak producer & + & - \\
\hline E7 & $\mathrm{O}_{78}$ & Weak producer & + & - \\
\hline E8 & $\mathrm{O}_{86}$ & Weak producer & - & - \\
\hline E9 & $\mathrm{O}_{26}$ & Weak producer & - & + \\
\hline E10 & $\mathrm{O}_{86}$ & Weak producer & + & - \\
\hline E11 & $\mathrm{O}_{78}$ & Weak producer & - & - \\
\hline E12 & $\mathrm{O}_{86}$ & Weak producer & + & - \\
\hline E13 & $\mathrm{O}_{86}$ & Weak producer & + & 2 \\
\hline E14 & $\mathrm{O}_{164}$ & Weak producer & + & $14.3 \%$ \\
\hline Number of positive isolates & 14 & 10 & \\
\hline
\end{tabular}

\section{5- Results of antimicrobial susceptibility testing:}

Results of evaluation susceptibility of the isolates to the tested antibiotics in this study are presented in Tables (5) and (6). It was found that all the isolates were resistant to 7 of the tested antibiotics namely ampicillin, amoxicillin/clavulanic acid, cefazolin, cefotaxime kanamycin, clindamycin and nitrofurantoin. Concerning the other three antibiotics used, all the isolates were sensitive to chloramphenicol and oxytetracycline except $(42.9 \%)$ and $(85.7 \%)$ of $E$. coli isolates respectively and to azithromycin except (35.7\%) of E. coli isolates and K. pneumoniae isolate.

Table 5: Results of antimicrobial susceptibility of E. coli isolates.

\begin{tabular}{|c|c|c|c|c|c|c|c|c|c|c|c|}
\hline E. coli isolate & AMP & AMC & $\mathrm{CZ}$ & CTX & $\mathrm{K}$ & AZM & DA & $\mathrm{T}$ & $\mathrm{C}$ & $\mathrm{F}$ & MDR \\
\hline E1 & $\mathrm{R}$ & $\mathrm{R}$ & $\bar{R}$ & $\mathrm{R}$ & $\bar{R}$ & $\mathrm{R}$ & $\mathrm{R}$ & $\bar{R}$ & $\bar{R}$ & $\bar{R}$ & 10 \\
\hline $\bar{E} 2$ & $\overline{\mathrm{R}}$ & $\overline{\mathrm{R}}$ & $\overline{\mathrm{R}}$ & $\overline{\mathrm{R}}$ & $\bar{R}$ & $\bar{S}$ & $\overline{\mathrm{R}}$ & $\overline{\mathrm{R}}$ & $\mathrm{S}$ & $\bar{R}$ & 8 \\
\hline E3 & $\overline{\mathrm{R}}$ & $\overline{\mathrm{R}}$ & $\mathrm{R}$ & $\overline{\mathrm{R}}$ & $\overline{\mathrm{R}}$ & $\bar{S}$ & $\bar{R}$ & $\overline{\mathrm{R}}$ & $\overline{\mathrm{R}}$ & $\overline{\mathrm{R}}$ & $\overline{9}$ \\
\hline E4 & $\mathrm{R}$ & $\mathrm{R}$ & $\mathrm{R}$ & $\mathrm{R}$ & $\mathrm{R}$ & $\mathrm{R}$ & $\mathrm{R}$ & $\mathrm{R}$ & $\mathrm{R}$ & $\mathrm{R}$ & 10 \\
\hline E5 & $\bar{R}$ & $\bar{R}$ & $\bar{R}$ & $\bar{R}$ & $\bar{R}$ & $\bar{S}$ & $\bar{R}$ & $\bar{R}$ & $\mathrm{I}$ & $\mathrm{R}$ & 8 \\
\hline E6 & $\mathrm{R}$ & $\mathrm{R}$ & $\mathrm{R}$ & $\mathrm{R}$ & $\mathrm{R}$ & $\mathrm{R}$ & $\mathrm{R}$ & $\mathrm{R}$ & $\mathrm{R}$ & $\mathrm{R}$ & 10 \\
\hline E7 & $\mathrm{R}$ & $\mathrm{R}$ & $\mathrm{R}$ & $\mathrm{R}$ & $\mathrm{R}$ & $\mathrm{R}$ & $\mathrm{R}$ & $\mathrm{R}$ & $\mathrm{R}$ & $\mathrm{R}$ & 10 \\
\hline E8 & $\mathrm{R}$ & $\mathrm{R}$ & $\mathrm{R}$ & $\mathrm{R}$ & $\mathrm{R}$ & $S$ & $\mathrm{R}$ & $\mathrm{I}$ & $\mathrm{S}$ & $\mathrm{R}$ & 7 \\
\hline E9 & $\mathrm{R}$ & $\mathrm{R}$ & $\mathrm{R}$ & $\mathrm{R}$ & $\mathrm{R}$ & $S$ & $\mathrm{R}$ & $\mathrm{R}$ & $\mathrm{I}$ & $\mathrm{R}$ & 8 \\
\hline E10 & $\overline{\mathrm{R}}$ & $\overline{\mathrm{R}}$ & $\bar{R}$ & $\overline{\mathrm{R}}$ & $\bar{R}$ & $\bar{S}$ & $\overline{\mathrm{R}}$ & $\overline{\mathrm{R}}$ & $\bar{S}$ & $\overline{\mathrm{R}}$ & 8 \\
\hline E11 & $\mathrm{R}$ & $\mathrm{R}$ & $\mathrm{R}$ & $\mathrm{R}$ & $\mathrm{R}$ & $\mathrm{R}$ & $\mathrm{R}$ & $\mathrm{R}$ & $\mathrm{S}$ & $\mathrm{R}$ & 9 \\
\hline E12 & $\mathrm{R}$ & $\mathrm{R}$ & $\mathrm{R}$ & $\mathrm{R}$ & $\mathrm{R}$ & $\mathrm{S}$ & $\mathrm{R}$ & $\mathrm{I}$ & $\mathrm{S}$ & $\mathrm{R}$ & 7 \\
\hline E13 & $\bar{R}$ & $\overline{\mathrm{R}}$ & $\overline{\mathrm{R}}$ & $\bar{R}$ & $\overline{\mathrm{R}}$ & $\mathrm{S}$ & $\bar{R}$ & $\overline{\mathrm{R}}$ & $\bar{I}$ & $\overline{\mathrm{R}}$ & 8 \\
\hline E14 & $\mathrm{R}$ & $\mathrm{R}$ & $\mathrm{R}$ & $\mathrm{R}$ & $\mathrm{R}$ & $\mathrm{S}$ & $\mathrm{R}$ & $\mathrm{R}$ & $\mathrm{R}$ & $\mathrm{R}$ & 9 \\
\hline $\begin{array}{c}\text { Number of } \\
\text { sensitive isolates }\end{array}$ & 0 & 0 & 0 & 0 & 0 & 9 & 0 & 2 & 8 & 0 & \\
\hline$\%$ & 0 & 0 & 0 & 0 & 0 & 64.3 & 0 & 14.3 & 57.1 & 0 & \\
\hline
\end{tabular}

$\mathrm{R}=$ resistant, $\mathrm{S}=$ sensitive and $\mathrm{I}=$ intermediate. 
Table 6: Results of antimicrobial susceptibility of S. Typhimurium isolates.

\begin{tabular}{cccccccccccc}
\hline $\begin{array}{c}\text { S. Typhimurium } \\
\text { isolate }\end{array}$ & AMP & AMC & CZ & CTX & K & AZM & DA & T & C & F & MDR \\
\hline S1 & $\mathrm{R}$ & $\mathrm{R}$ & $\mathrm{R}$ & $\mathrm{R}$ & $\mathrm{R}$ & $\mathrm{S}$ & $\mathrm{R}$ & $\mathrm{S}$ & $\mathrm{S}$ & $\mathrm{R}$ & 7 \\
\hline $\mathrm{S} 2$ & $\mathrm{R}$ & $\mathrm{R}$ & $\mathrm{R}$ & $\mathrm{R}$ & $\mathrm{R}$ & $\mathrm{S}$ & $\mathrm{R}$ & $\mathrm{S}$ & $\mathrm{S}$ & $\mathrm{R}$ & 7 \\
\hline $\mathrm{S} 3$ & $\mathrm{R}$ & $\mathrm{R}$ & $\mathrm{R}$ & $\mathrm{R}$ & $\mathrm{R}$ & $\mathrm{S}$ & $\mathrm{R}$ & $\mathrm{S}$ & $\mathrm{S}$ & $\mathrm{R}$ & 7 \\
\hline $\mathrm{S} 4$ & $\mathrm{R}$ & $\mathrm{R}$ & $\mathrm{R}$ & $\mathrm{R}$ & $\mathrm{R}$ & $\mathrm{S}$ & $\mathrm{R}$ & $\mathrm{I}$ & $\mathrm{S}$ & $\mathrm{R}$ & 7 \\
\hline $\mathrm{S} 5$ & $\mathrm{R}$ & $\mathrm{R}$ & $\mathrm{R}$ & $\mathrm{R}$ & $\mathrm{R}$ & $\mathrm{S}$ & $\mathrm{R}$ & $\mathrm{I}$ & $\mathrm{S}$ & $\mathrm{R}$ & 7 \\
\hline $\mathrm{S} 6$ & $\mathrm{R}$ & $\mathrm{R}$ & $\mathrm{R}$ & $\mathrm{R}$ & $\mathrm{R}$ & $\mathrm{S}$ & $\mathrm{R}$ & $\mathrm{I}$ & $\mathrm{S}$ & $\mathrm{R}$ & 7 \\
\hline $\begin{array}{c}\text { Number of } \\
\text { sensitive isolates }\end{array}$ & 0 & 0 & 0 & 0 & 0 & 6 & 0 & 6 & 6 & 0 & \\
\hline$\%$ & 0 & 0 & 0 & 0 & 0 & 100 & 0 & 100 & 100 & 0 & \\
\hline
\end{tabular}

$\mathrm{R}=$ resistant, $\mathrm{S}=$ sensitive and $\mathrm{I}=$ intermediate.

\section{6- Results of isolates investigation for some genes by PCR:}

In this study, screening E. coli, S. Typhimurium and $K$. pneumoniae isolates by conventional PCR for presence of eaeA, invA and magA genes respectively revealed that $(21.4 \%)$ of $E$. coli isolates harbor eaeA gene (Fig. 1) and all $S$. Typhimurium isolates harbor invA gene (Fig. 2) while $K$. pneumoniae isolate didn't harbor magA gene (Fig. 3). On the other hand, screening these isolates by the same technique for presence of Intl, floR and $Q a c A / B$ genes revealed that all the isolates harbor Intl gene (Fig. 4) and floR gene (Fig. 5) while only $(21.4 \%)$ and $(33.3 \%)$ of $E$. coli and $S$. Typhimurium isolates harbor $Q a c A / B$ genes (Fig. 6) respectively. PCR results for E. coli and $S$. Typhimurium isolates were summarized in Tables (7) and (8) respectively.

Table 7: Prevalence of $e a e A, I n t 1$, floR and $Q a c A / B$ genes among E. coli isolates by PCR.

\begin{tabular}{ccccc}
\hline E. coli isolate & eaeA gene & Int1 gene & floR gene & QacA/B gene \\
\hline E1 & - & + & + & - \\
\hline E2 & + & + & + & - \\
\hline E3 & + & + & + & - \\
\hline E4 & - & + & + & + \\
\hline E5 & - & + & + & - \\
\hline E6 & - & + & + & - \\
\hline E7 & - & + & + & - \\
\hline E8 & - & + & + & - \\
\hline E9 & - & + & + & + \\
\hline E10 & - & + & + & + \\
\hline E11 & - & + & + & - \\
\hline E12 & + & + & + & 3 \\
\hline E13 & - & + & 14 & $21.4 \%$ \\
\hline E14 & - & 14 & $100 \%$ & \\
\hline $\begin{array}{c}\text { Number of } \\
\text { positive isolates }\end{array}$ & 3 & $100 \%$ & & + \\
\hline$\%$ & $21.4 \%$ & & + & \\
\hline
\end{tabular}


Table 8: Prevalence of invA, Int 1, floR and $Q a c A / B$ genes among S. Typhimurium isolates by PCR.

\begin{tabular}{ccccc}
\hline S. Typhimurium isolate & invA gene & Int1 gene & floR gene & QacA/B gene \\
\hline S1 & + & + & + & - \\
\hline S2 & + & + & + & - \\
\hline S3 & + & + & + & + \\
\hline S4 & + & + & + & - \\
\hline S5 & + & + & + & + \\
\hline S6 & + & + & 6 & - \\
\hline Number of positive isolates & 6 & 6 & $100 \%$ & $33.3 \%$ \\
\hline$\%$ & $100 \%$ & $100 \%$ & & \\
\hline
\end{tabular}

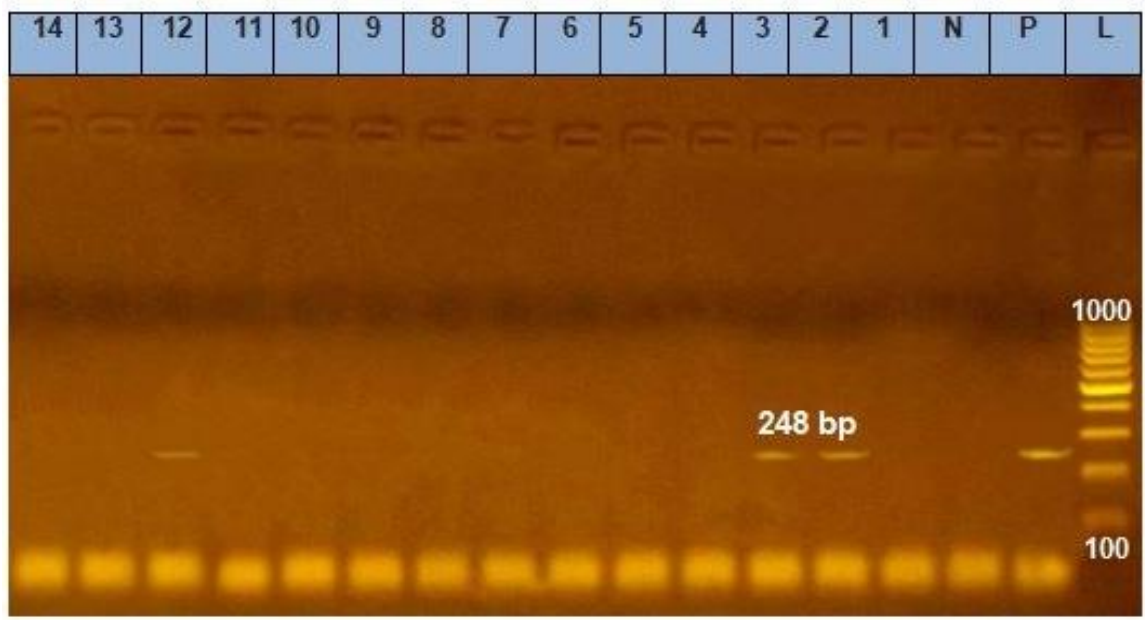

Fig. (1): Agar gel electrophoresis for products of PCR using specific primers targeting eaeA gene in E. coli isolates. Lane L: molecular weight marker 100 base pair, lane P: positive control, lane N: negative control and lanes 1-14: DNA extracted from E. coli isolates (E1:E14 respectively) showing positive bands at 248-bp in isolates E2, E3 and E12.

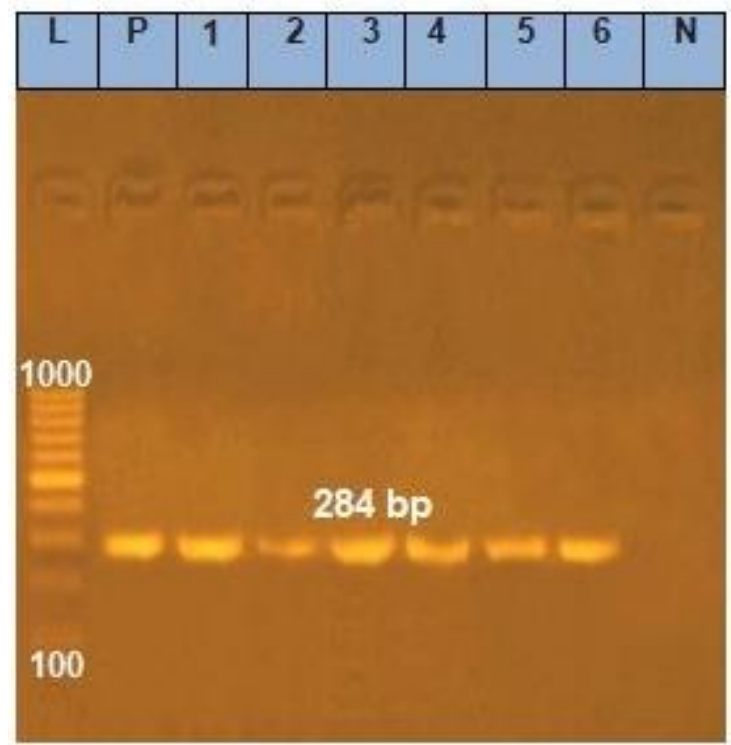

Fig. (2): Agar gel electrophoresis for products of PCR using specific primers targeting invA gene in S. Typhimurium isolates. Lane L: molecular weight marker 100 base pair, lane P: positive control, lane N: negative control and lanes 1-6: DNA extracted from S. Typhimurium isolates (S1:S6 respectively) showing positive bands at 284-bp in all the isolates. 


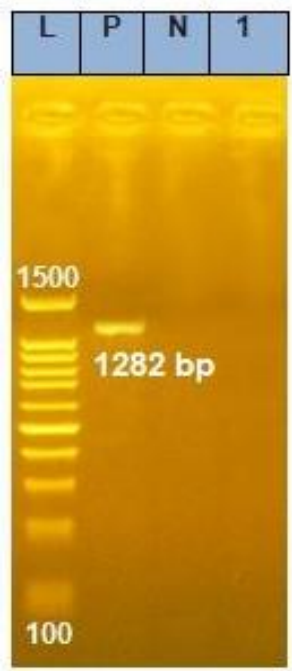

Fig. (3): Agar gel electrophoresis for products of PCR using specific primers targeting magA gene in K. pneumoniae isolate. Lane L: molecular weight marker 100 base pair, lane P: positive control, lane N: negative control and lane 1: DNA extracted from $K$. pneumoniae isolate showing no bands at 1282-bp (Negative).

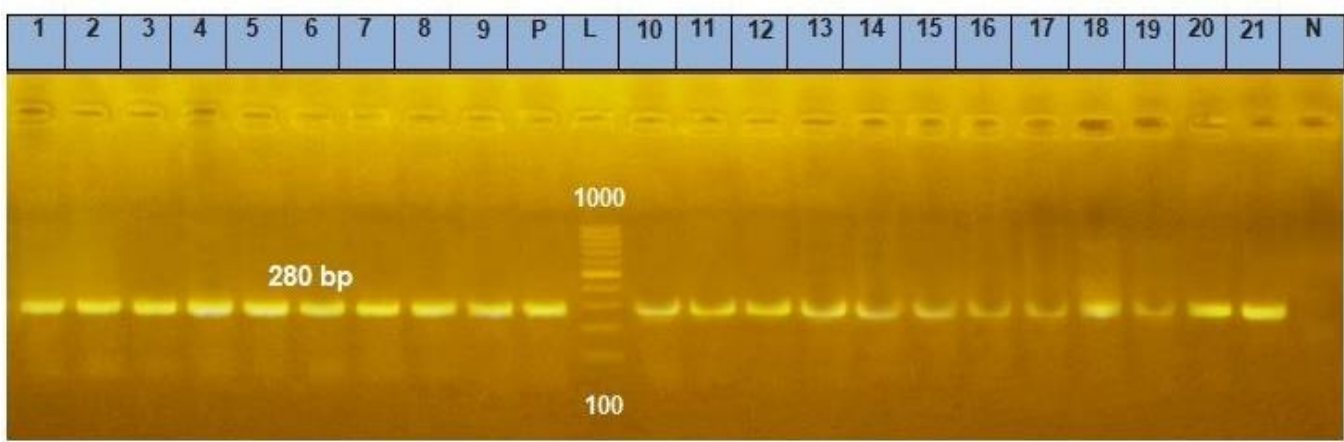

Fig. (4): Agar gel electrophoresis for products of PCR using specific primers targeting Intl gene in the isolates. Lane L: molecular weight marker 100 base pair, lane P: positive control, lane $\mathrm{N}$ : negative control and lane 1: DNA extracted from $K$. pneumoniae isolate, lanes 2-7: DNA extracted from $S$. Typhimurium isolates (S1:S6 respectively) and lanes 8-21: DNA extracted from E. coli isolates (E1:E14 respectively). All the isolates showing positive bands at 280-bp.

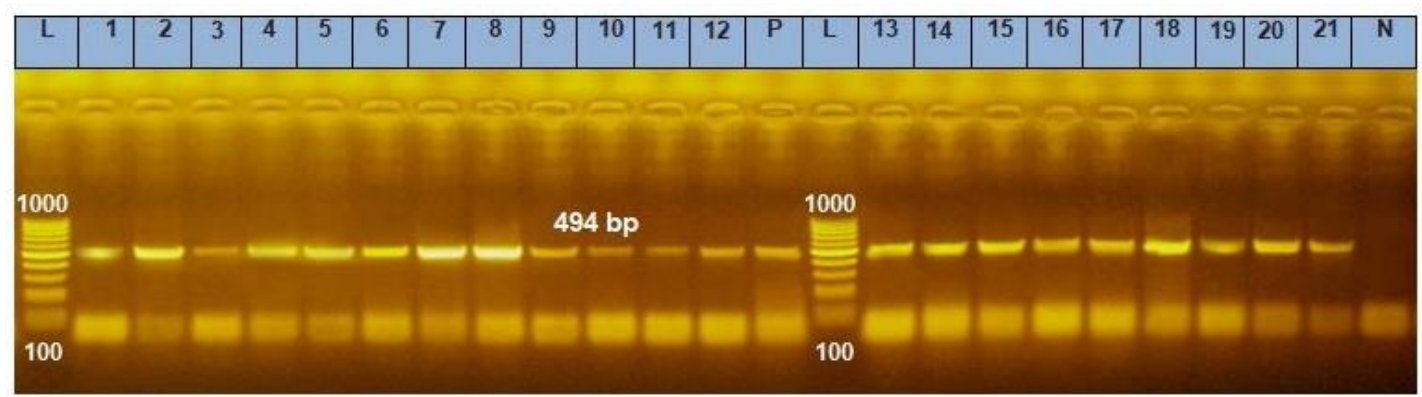

Fig. (5): Agar gel electrophoresis for products of PCR using specific primers targeting floR gene in the isolates. Lane L: molecular weight marker 100 base pair, lane P: positive control, lane $\mathrm{N}$ : negative control and lane 1: DNA extracted from $K$. pneumoniae isolate, lanes 2-7: DNA extracted from S. Typhimurium isolates (S1:S6 respectively) and lanes 8-21: DNA extracted from E. coli isolates (E1:E14 respectively). All the isolates showing positive bands at 494-bp. 


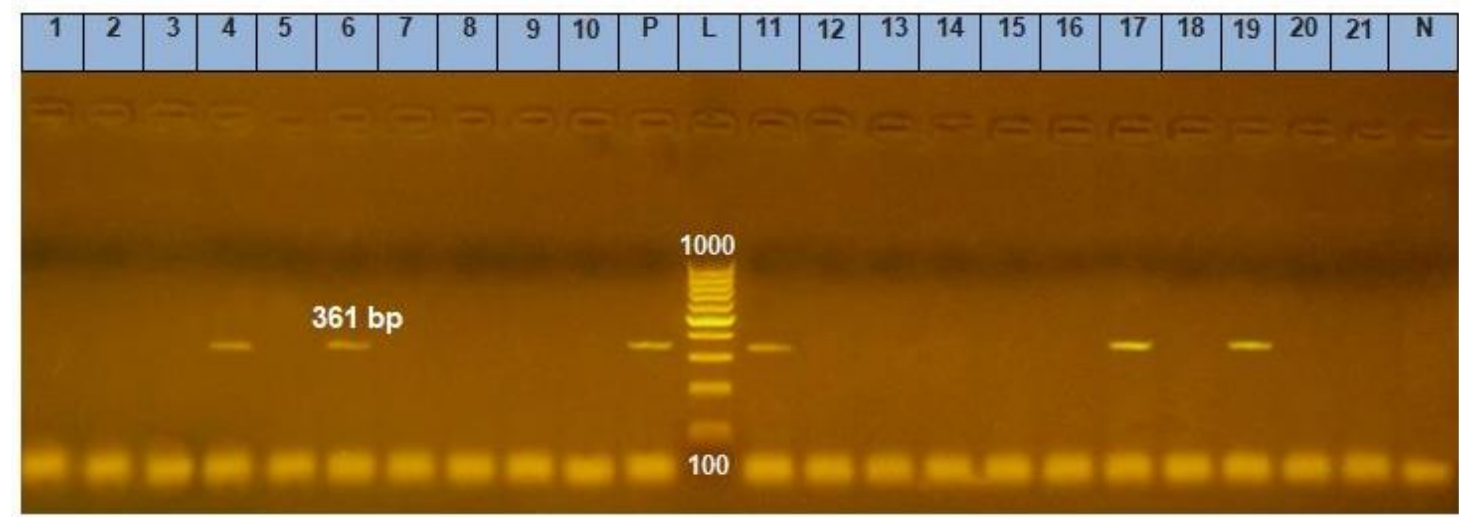

Fig. (6): Agar gel electrophoresis for products of PCR using specific primers targeting $Q a c A / B$ gene in the isolates. Lane L: molecular weight marker 100 base pair, lane P: positive control, lane N: negative control and lane 1: DNA extracted from K. pneumoniae isolate showing no bands at 361-bp (Negaive), lanes 2-7: DNA extracted from S. Typhimurium isolates (S1:S6 respectively) showing positive bands at 361-bp in isolates S3 and S5 and lanes 8-21: DNA extracted from $E$. coli isolates (E1:E14 respectively) showing positive bands at 361-bp in isolates E4, E10 and E12.

\section{DISCUSSION}

Quail farming is considered as one of the most alternative sources for meat production to cover the deficiency in the animal protein in Egypt (Abd El-Dayem et al., 2020). Early mortality of quail chicks is one of the limiting factors in breeding of quails (Boroomand et al., 2018). Appropriate knowledge about diseases affecting quails is necessary for the suitable control and preventive programs in quail production. The present study identified the important role of some Enterobacteriaceae members as a cause of early mortality of quail chicks in Egypt through isolation and identification of E. coli, $S$. Typhimurium and $K$. pneumoniae isolates from the examined quail chicks with percentage of $(17.5 \%),(7.5 \%)$ and $(1.25 \%)$ respectively. Our results agreed with those of Abd El-Galil et al. (1993) who isolated E.coli and K. pneumoniae from the dead quails chicks at $1^{\text {st }}$ ten day of life with percentage of (18\%) and (2\%) respectively. Also, our results agreed with results of El-Demerdash et al. (2013) and Boroomand et al. (2018) about isolation of the same bacterial species from early mortality investigations of quail chicks, but with higher rates of the isolates and which could be attributed to difference of the geographical areas, managemental practices and climate. ElDemerdash et al. (2013) isolated E. coli,
Salmonella spp. and Klebsiella spp. from freshly dead and/or moribund Japanese quails chicks aged between 2 days and 3 weeks with percentage of $(38.75 \%),(7.5 \%)$ and $(6.25 \%)$ respectively. Boroomand et al. (2018) investigated Enterobacteriaceae responsible for early mortality in Japanese quail chicks and their results revealed isolation of $E$. coli, Salmonella spp. and $K$. pneumoniae with percentage of (44\%), (8\%) and (8\%) respectively.

In this study, the infected quail chicks showed no significant clinical signs but Post-mortem lesions in dead and sacrificed chicks included congestion in the internal organs, pericarditis, abdominal air sacculitis, typhilitis and urolithiasis. Similar post-mortem lesions recorded by Ameh et al. (2011) and Kabir (2010).

In this study, serotyping of $E$. coli isolates revealed that $E$. coli isolates belonged to 5 different $\mathrm{O}$-serogroups including $\mathrm{O}_{86}, \mathrm{O}_{78}, \mathrm{O}_{26}$, $\mathrm{O}_{55}$ and $\mathrm{O}_{164}$ in addition to 2 nontypeable isolates as illustrated in Table (3). Consistent with our findings, Farghaly et al. (2017), Ibrahim (2019) and Abd El-Dayem et al. (2020) isolated $E$. coli $\mathrm{O}_{78}$ from the diseased quails in Egypt, Abd El-Dayem et al. (2020) also isolated E. coli $\mathrm{O}_{55}$ from such quail and 
Dipineto et al. (2014) isolated E. coli $\mathrm{O}_{26}$ from common quails in Italy. On the other hand, all Salmonella isolates in this study were serologically identified as $S$. Typhimurium. Consistent with our findings, S. Typhimurium was isolated from quail chicks by Mosaad et al. (2000) and Boroomand et al. (2018). Isolation of $S$. Typhimurium only in this study with absence of the other Salmonella serovars may be attributed to either the geographic or temporal variances in Salmonella colonization of the birds. Furthermore, it has major public health consequences for consumers because of the lack of routine control of Salmonella serovars in the developing countries.

Many researchers advocated use of Congo red binding test for distinguishing between pathogenic and non-pathogenic microorganisms in APEC study (Saha et al., 2020). In this study, all the isolates except $(28.6 \%)$ of $E$. coli isolates showed Congo red binding activity indicating their pathogenicity. Furthermore, virulence of our isolates was indicated from that all of them were weak biofilm producer except $(33.3 \%)$ of $S$. Typhimurium isolates. Regarding to hemolysis on blood agar, only (14.3\%) of E. coli isolates had hemolytic activity. A clear distinction between pathogenic and nonpathogenic bacteria couldn't be established based on hemolytic activity.

Antimicrobial agents are essential drugs for both human and animals, but some bacteria have showed complete or partial resistance to the different antibiotics in the recent years (Palanisamy and Bamaiyi, 2015). In the present study, all the isolates were resistant to 7 of the tested antibiotics (MDR) namely ampicillin, amoxicillin/clavulanic acid, cefazolin, cefotaxime kanamycin, clindamycin and nitrofurantoin. The high MDR to these antibiotics observed in this study could be related to their high indiscriminate use in poultry farming, more specifically in the quail breeding in area of study. Furthermore and according to our results, presence of class I integron gene in all these isolates could explain this MDR where it has found that MDR genes are clustered on individual mobile elements, most commonly on class 1 or class 2 integrons, which mean that their readily transferred and increase MDR bacterial population (Nikaido, 2009 and Dawes et al., 2010). Presence of such MDR bacteria in quails will result in a clear difficulty in prevention and control of the bacterial diseases affecting them and it also has epidemiological and public health implications represented in transfer of these MDR bacteria and the resistance genes to human and animals. Therefore, antibiotics use in quail farms must be prudent and supported by antibiogram tests before drug administration in addition to adoption of the strict hygienic measures. Concerning the other three tested antibiotics, all the isolates were sensitive to chloramphenicol and oxytetracycline except (42.9\%) and $(85.7 \%)$ of $E$. coli isolates respectively and to azithromycin except (35.7\%) of E. coli isolates and $K$. pneumoniae isolate. Our results agreed with those of Boris et al. (2012) and Boroomand et al. (2018) who reported that all Salmonella isolates were sensitive to chloramphenicol and oxytetracycline respectively and also, nearly similar with those of Boroomand et al. (2018) who reported that $(74.5 \%)$ of $E$. coli isolates were resistant to oxytetracycline.

The eaeA gene encodes intimin that enables the intimate attachment of $E$. coli to enterocytes (Ateba and Mbewe, 2014). In this study, eaeA gene was detected in $(21.4 \%)$ of $E$. coli isolates and specifically in serotypes $\mathrm{O}_{78}(\mathrm{E} 2)$ and $\mathrm{O}_{86}$ (E13) as illustrated in Table (7) and Figure (1). Presence of eaeA gene in $(21.4 \%)$ of $E$. coli isolates came in accordance with Abd ElDayem et al. (2020) who found eaeA gene in $(25 \%)$ of APEC isolates while it came incompatible with Yousef et al. (2015) who found eaeA gene in all APEC isolates and with Salehi and Ghanbarpour (2010) who didn't find $e a e A$ gene in all APEC isolates. Concerning $E$. coli serotypes, Eid et al. (2016) detected eaeA in E. coli serotypes $\mathrm{O}_{78}$ while Abd El-Dayem et al. (2020) didn't detect eaeA gene in this serotype.

Intestinal epithelium cells invasion is one of the earliest steps in the pathogenic cycle of 
Salmonella spp. (Galán et al., 1992). InvA gene encodes bacterial membrane protein essential for invasion of the host epithelial cells (Darwin and Miller, 1999). In this study, invA gene was detected in all S. Typhimurium isolates (100\%) as illustrated in Table (8) and Figure (2) which is similar to that was reported by Ahmed et al. (2016) and Ammar et al. (2018).

The magA gene contributes in bacterial virulence of $K$. pneumoniae (Fang et al., 2005). Presence of magA and rmpA genes in $K$. pneumoniae serotypes $\mathrm{K} 1$ and $\mathrm{K} 2$ make them more invasive and resistant to the phagocytosis (Younis et al., 2016). Our isolate of $K$. pneumoniae was negative for magA gene as illustrated Figure (3). Our finding is similar to that was reported by El Fertas-Aissani et al. (2013) who didn't find any positive isolate for magA gene in the examined strains from different human clinical samples while came inconsistence with that was reported by Younis et al. (2016) who found that (53.33\%) of the examined isolates were positive for magA gene but this difference may be attributed to the low number of our $K$. pneumoniae isolates $(\mathrm{n}=1)$. Furthermore, absence of magA gene wasn't expected finding where our $K$. pneumoniae isolate displayed a mucoid phenotype and magA gene has hyperviscous phenotype (Struve et al., 2005), so further studies are needed for clarification the exact role of $\mathrm{magA}$ in the hypermucoviscosity phenotype.

Bacteria can acquest the resistance genes via the mobile elements which help in dissemination and distribution of these genes among the different bacterial populations (Blair et al., 2015). Integrons are potent mobile genetic elements where their location on the plasmids, transposons and pathogenicity islands facilitate their transferring among the different bacteria (Firoozeh et al., 2019). Class 1 integrons have been frequently reported in gram negative bacterial isolates (Lima et al., 2014). In this study, it was found that all the isolates harbor Class 1 integrons gene as illustrated in Tables (7 and 8) and Fig. (4). In previous study, Antunes et al. (2006) reported lower prevalence of Class 1 integrons gene $(75.0 \%)$ among $S$. enterica isolated from different sources in Portugal. On the other hand, Dotto et al. (2014) detected Class I integrons in $(61.1 \%)$ of E. coli isolated from domestic and wild Lagomorphs in northern Italy.

Florfenicol is a derivative of chloramphenicol and it is only used for treatment of animals. Over the past decade, levels of the resistance to florfenicol and number of the resistant bacteria to it, have been increased due to the widespread use of florfenicol (Lu et al., 2018). As illustrated in Tables (7 and 8) and Fig. (5), screening our isolates by PCR for presence of floR gene that encodes florphenicol resistance revealed its presence in all the isolates. FloR gene was detected with somewhat lower prevalence in studies of Li et al. (2020) and ElSharkawy et al. (2017) who found that $(91.51 \%)$ of $E$. coli isolates and $(80 \%)$ of $S$. Typhimurium isolates harbor floR gene respectively. In this study, it was found that all the isolates were sensitive to chloramphenicol except $(42.9 \%)$ of $E$. coli isolates although they harbor floR gene that confers chloramphenicol resistance, this may be attributed to that this resistant gene is silent in vitro in these isolates or due to that chloramphenicol resistance may by expressed phenotypically through another resistance genes or another resistance factors aren't tested in this study.

In this study, it was found that only $(21.4 \%)$ and $(33.3 \%)$ of $E$. coli and S. Typhimurium isolates harbor $Q a c A / B$ gene respectively as illustrated in Tables (7 and 8) and Fig. (6). Our results came in accordance nearly with Ibrahim et al. (2019) who found $Q a c A / B$ gene in $(14.7 \%)$ of $E$. coli isolated from chickens in Egypt while it came incompatible with Enany et al. (2019) who reported that all the tested Salmonella isolated from environmental and avian sources in Egypt harbor $Q a c A / B$ gene and with Nabil and Yonis (2019) who can't detect QacA/B gene in Salmonella isolated from broiler chickens in Egypt. This difference may be attributed to the differences in farm management and geographic location. 


\section{ACKNOWLEDGMENTS}

The authors would like to thank Dr. Ahmed Shawky Helmy, Reference Laboratory for Veterinary Quality Control on Poultry Production, Giza, Egypt for his great help to finish this work.

\section{CONCLUSION}

According to results of this study, E. coli and $S$. Typhimurium are one of the major causes of early mortality in Japanese quail chicks. E. coli, $S$. Typhimurium and $K$. pneumoniae isolated from quail chicks were pathogenic, harbor Class 1 integrons gene and they showed marked resistance to several antibiotics commonly used in poultry and human in Egypt (MDR). Therefore, more attention should be driven to the biosecurity measures in quail hatcheries and farms in Egypt and prudent use of antibiotics supported by antibiogram tests before drug administration in quail farms.

\section{AUTHOR'S CONTRIBUTION}

All authors contributed equally in this work. They read and approved the final manuscript.

\section{CONFLICT OF INTEREST}

The authors declare that they have no conflict of interest.

\section{REFERENCES}

Abd El-Dayem, G.A.; Ramadan, A.H. and Ali, H.S. (2020): Prevalence of virulence factors and antibiotic resistance genes in shiga toxin-producing Escherichia coli isolated from quails. Assiut Vet. Med. J., 66 (167):84-99.

Abd El-Ghany, W.A. (2019): A comprehensive review on the common emerging diseases in quails. J. World Poult. Res., 9(4): 160174.

Abd El-Glil, Y.; Atia, A.; Helmy, S.; ElNaeneey, E. and Hamouda, A. (1993): Studies on the bacterial causes of early quail mortalities. Zagazig Vet. J. 21(3):
547-557.

Ahmed, H.A.; El-Hofy, F.I.; Shafik, S.M.; Abd El Rahman, M.A. and El Said, G.A. (2016): Characterization of virulenceassociated genes, antimicrobial resistance genes and class 1 Integrons in Salmonella enterica serovar Typhimurium isolates from chicken meat and humans in Egypt. Foodborne Pathog. Dis., 13(6):281-288.

Ameh, J.; Adamu, J. and Ikpa, T. (2011): Experimental infection of chicks with avian Enteropathogenic Escherichia coli (APEC) Serotype O78: K80. African Scientist, 12: (1), 27-32.

Ammar, A.M.; Abdeen, E.E.; Abo-Shama, U.H.; Fekry, E. and Elmahallawy, E.K. (2018): Molecular characterization of virulence and antibiotic resistance genes among Salmonella serovars isolated from broilers in Egypt. Lett. Appl. Microbiol., 68:188-195.

Antunes, P.; Machado, J. and Peixe, L. (2006): Characterization of antimicrobial resistance and class 1 and 2 integrons in Salmonella enterica isolates from different sources in Portugal. J. Antimicrob. Chemother., 58: 297-304.

Ateba, C. and Mbewe, M. (2014): Genotypic Characterization of Escherichia coli O157:H7 isolates from different sources in the North-West Province, South Africa, using Enterobacterial Repetitive Intergenic Consensus PCR Analysis. Int. J. Mol. Sci., 15 (6): 9735-9747.

Barnes, H.J. and Gross, W.B. (1997): Colibacillosis. In: Calnek, B.W.; Barens, H.J.; Beard, C.W.; McDougald, L.R. and Saif, Y.M. (Eds.), Diseases of Poultry, $10^{\text {th }}$ Ed. Iowa State University Press, Ames, Iowa, pp: 131-41.

Bisi-Johnson, M.A.; Obi, C.L.; Vasaikar, S.D.; Baba, K.A. and Hattori, T. (2011): Molecular basis of virulence in clinical isolates of Escherichia coli and Salmonella species from a tertiary hospital in the Eastern Cape, South Africa. Gut Pathog., 2011, 3:9.

Blair, J.; Webber, M.; Baylay, A.; Ogbolu, D. and Piddock, L. (2015): Molecular mechanisms of antibiotic resistance. Nat. 
Rev. Microbiol., 13: 42-51.

Boris, H.; Borka, S.; Gordan, K. and Fani, K. (2012): Antimicrobial resistance and serotyping of Salmonella enterica subsp. enterica isolated from poultry in Croatia. Vet. Arhiv., 82:371-381.

Boroomand, Z.; Jafari, R.; Gharibi, D. and Kazemi, K. (2018): An Investigation into Enterobacteriaceae responsible for early mortality in Japanese quail chicks and their antibiotic susceptibility patterns. Arch. Razi Inst., 73(4): 277-285.

Capuano, F.; Mancusi, A.; Capparelli, R.; Esposito, S. and Proroga, Y.T. (2013): Characterization of drug resistance and virulotypes of Salmonella strains isolated from food and humans. Foodborne Pathog. Dis., 10 (11): 963-968.

CLSI (2006): Methods for Antimicrobial Broth Dilution and Disk Diffusion Susceptibility Testing of Bacteria Isolated From Aquatic Animals. 2 $2^{\text {nd }}$ Ed. CLSI guideline VET03. Wayne, PA: Clinical and Laboratory Standards Institute.

Da Cunha, R.G. (2009): Quail meat-an undiscovered alternative. World Poult., 25:12-14.

Darwin, K.H. and Miller, V.L. (1999): Molecular basis of the interaction of Salmonella with the intestinal mucosa. Clin. Microbiol. Rev., 12, 405-428.

Darwish, W.S.; Eldaly, E.; El-Abbasy, M.; Ikenaka, Y.; Nakayama, S. and Ishizuka, M. (2013): Antibiotic residues in food: African scenario. Jap. J. Vet. Res., 61: S13-S22.

Dawes, F.; Kuzevski, A.; Bettelheim, K.; Hornitzky, M.; Djordjevic, S. and Walker, M. (2010): Distribution of class 1 integrons with IS 26-mediated deletions in their 3'-conserved segments in Escherichia coli of human and animal origin. PLoS ONE, 5:e12754.

Dipineto, L.; Russo, T.P.; Gargiulo, A.; Borrelli, L.; De Luca Bossa, L.M.; Santaniello, A.; Menna, P.L. and Fioretti, A. (2014): Prevalence of enteropathogenic bacteria in common quail (Coturnix coturnix). Avian Pathol., 43(6): 498-500.

Dotto, G.; Giacomelli, M.; Grilli, G.; Ferrazzi,
V.; Carattoli, A.; Fortini, D. and Piccirillo, A. (2014): High prevalence of oqxAB in Escherichia coli isolates fromdomestic and wild lagomorphs in Italy. Microbial. Drug Resistance, 20 (2): 118-123.

Doublet, B.; Lailler, R.; Meunier, D.; Brisabois, A.; Boyd, D.; Mulvey, M.R.; Chaslus-Dancla, E. and Cloeckaert, A. (2003): Variant Salmonella genomic island 1 antibiotic resistance gene cluster in Salmonella enterica Serovar Albany. Emerg. Infect. Dis., 9 (5): 585-591.

Edwards, P.R. and Ewing, W.H. (1972): Identification of Enterobacteriaceae, $3^{\text {rd }}$ Ed. Burgess Publishing Co., Minneapolis.

Eid, H.I.; Algammal, A.M.; Nasef, S.A.; Elfeil, W.K. and Mansour, G.H. (2016): Genetic variation among avian pathogenic $E$. coli strains isolated from broiler chickens. Asian J. Anim. Vet. Adv., 11 (6): 350356.

El Fertas-Aissani, R.; Messai, Y.; Alouache, S. and Bakour, R. (2013): Virulence profiles and antibiotic susceptibility patterns of Klebsiella pneumoniae strains isolated from different clinical specimens. Pathologie Biologie, 61: 209-216.

El-Demerdash, M.Z.; Hanan, M.F.A. and Asmaa, E.A. (2013): Studies on mortalities in baby quail chicks. The $6^{\text {th }}$ Animal Wealth Research Conf. in the Middle East \& North Africa, Hurghada, pp. 63 - 76.

El-Sharkawy, H.; Tahoun, A.; El-Gohary, A.A.; El-Abasy, M.; El-Khayat, F.; Gillespie, T.; Kitade, Y.; Hafez, H.M.; Neubauer, H. and El-Adawy, H. (2017): Epidemiological, molecular characterization and antibiotic resistance of Salmonella enterica serovars isolated from chicken farms in Egypt. Gut Pathog., 9:8.

Enany, M.E.; Algammal, A.M.; Nasef, S.A.; Abo-Eillil, S.A.M.; Bin-Jumah, M.; Taha, A.E. and Allam, A.A. (2019): The occurrence of the multidrug resistance (MDR) and the prevalence of virulence genes and QACs resistance genes in $E$. coli isolated from environmental and 
avian sources. AMB Expr., 9: 192.

Fang, F.C.; Sandler, N. and Libby, S.J. (2005): Liver abscess caused by magA Klebsiella pneumoniae in North America. J. Clin. Microbiol., 43: 991-992.

Farghaly, E.M.; Samy, A. and Roshdy, H. (2017): Wide prevalence of critically important antibiotic resistance in Egyptian Quail farms with mixed infections. Vet. Scie. Res. Review, 3(1): 17-24.

Firoozeh, F.; Mahluji, Z.; Khorshidi, A. and Zibaei, M. (2019): Molecular characterization of class 1,2 and 3 integrons in clinical multi-drug resistant Klebsiella pneumoniae isolates. Antimicrob. Resist. Infect. Control, 8:59.

Galán, J.E.; Ginocchio, C. and Costeas, $P$. (1992): Molecular and functional characterization of the Salmonella invasion gene invA: homology of InvA to members of a new protein family. J. Bacteriol., 174 (13): 4338-4349.

Grimont, P.A. and Weill, F.X. (2007): Antigenic formulas of the Salmonella Servers, WHO Collaborating Center for reference and research on Salmonella, Paris ( $\left(9^{\text {th }} E d\right): 1-166$.

Hassan, A.M.; Mohammed, D.A.; Hussein, K.N. and Hussen, S.H. (2017): Comparison among three lines of quail for egg quality characters. Science Journal of University of Zakho, 5 (4): 296-300.

Haynes, R.L. and Smith, T.W. (2003): Hatchery Management Guide for Game Birds and Small Poultry Flock Owners. Online Publication of Mississippi State University.

Hendriksen, R.S.; Vieira, A.R.; Karlsmose, S.; Lo Fo, W.D.; Jensen, A.B.; Wegener, H.C. and Aarestrup, F.M. (2011): Global monitoring of Salmonella serovar distribution from the World Health Organization Global Foodborne Infections Network Country Data Bank: Results of quality assured laboratories from 2001 to 2007. Foodborne Pathog. Dis., 8: 887-900.

Holt, J.G.; Krieg, N.R.; Sneath, P.H.; Staley, J.T. and Williams, S.T. (1994): Bergey's
Manual of Determinative Bacteriology. $9^{\text {th }}$ Ed., Lippincott Williams \& Wilkins, USA.

Ibrahim, W.A.; Marouf, S.A.; Erfan, A.M.; Nasef, S.A. and El Jakee, J.K. (2019): The occurrence of disinfectant and antibiotic-resistant genes in Escherichia coli isolated from chickens in Egypt. Vet. World, 12: 141-145.

Ibrahim, W.F. (2019): Isolation, identification and antimicrobial susceptibility testing of recent $E$. coli serotypes from Japanese Quails reared in Sharkia Governorate, Egypt. Damanhour Journal of Veterinary Sciences, 1(2): 14-17.

Jahantigh, M.; Rashki, A. and Najimi, M. (2013): A study on bacterial flora and antibacterial resistance of yolk sac infection in Japanese quail (Coturnix japonica). Comp. Clin. Pathol., 22: 645648

Kabir, S.M.L. (2010): Avian Colibacillosis and Salmonellosis: A closer look at epidemiology, pathogenesis, diagnosis, control and public health concerns. Int. J. Environ. Res. Public Health, 7: 89-114.

Khoshbakht, R.; Seifi, S.; Karimi, A. and Khosravi, M. (2017): Molecular identification of Campylobacter, Arcobacter, and Salmonella in Japanese quail (Coturnix japonica) reared in farms of Northern Iran. J. Food Qual. Hazards Control, 4: 58-62.

Li, P.; Zhu, T.; Zhou, D.; Lu, W.; Liu, H.; Sun, Z.; Ying, J.; Lu, J.; Lin, X.; Li, K.; Ying, J.; Bao, Q. and Xu, T. (2020): Analysis of resistance to florfenicol and the related mechanism of dissemination in different animal-derived bacteria. Front. Cell. Infect. Microbiol., 10, 369.

Lima, A.M.; de Melo, M.E.; Alves, L.C.; Brayner, F.A. and Lopes, A.C. (2014): Investigation of class 1 integrons in Klebsiella pneumoniae clinical and microbiota isolates belonging to different phylogenetic groups in Recife, State of Pernambuco. Rev. Soc. Bras. Med. Trop., 47: 165-169.

Lu, J.; Zhang, J.; Xu, L.; Liu, Y.; Li, P.; Zhu, T.; Cheng, C.; Lu, S.; Xu, T.; Yi, H.; Li, 
K.; Zhou, W.; Li, P.; Ni, L. and Bao, Q. (2018): Spread of the florfenicol resistance floR gene among clinical Klebsiella pneumoniae isolates in China. Antimicrob. Resist. Infect. Control, 7: 127

Magiorakos, A.P.; Srinivasan, A.; Carey, R.B.; Carmeli, Y.; Falagas, M.E.; Giske, C.G.; Harbarth, S.; Hindler, J.F.; Kahlmeter, G.; Olsson-Liljequist, B.; Paterson, D.L.; Rice, L.B.; Stelling, J.; Struelens, M.J.; Vatopoulos, A.; Weber, J.T. and Monnet, D.L. (2012): Multidrug-resistant, extensively drug-resistant and pandrugresistant bacteria: an international expert proposal for interim standard definitions for acquired resistance. Clin. Microbiol. Infect., 18: 268-281.

Mahon, C.R. and Lehman, D.C. (2019): Textbook of Diagnostic Microbiology. $6^{\text {th }}$ Ed., Elsevier Inc., USA.

Mellata, M.; Touchman, J.W. and Curtiss, R. (2009): Full sequence and comparative analysis of the plasmid pAPEC-1 of avian pathogenic E. coli $\chi 7122(\mathrm{O} 78: \mathrm{K} 80: \mathrm{H} 9)$. PLoS One, 4 (1): e4232.

Melo, P.D.; Ferreira, L.M.; Filho, A.N.; Zafalon, L.F.; Vicente, H.I. and Souza, V.D. (2013): Comparison of methods for the detection of biofilm formation by Staphylococcus aureus isolated from bovine subclinical mastitis. Braz. J. Microbiol., 44: 119-124.

Mosaad, A.A.; El-Shorbagy, M.A. and ElBoraei (2000): Studies on Salmonellosis in quiles. Minufiya Veterinary Medical Journal, 1 (1): 119-128.

Nabil, N.M. and Yonis, A.E. (2019): Isolation of Salmonella characterized by biofilm formation and disinfectant resistance from broiler chickens. A. J. V. S., 62(2): 26-36.

Nikaido, H. (2009): Multidrug resistance in bacteria. Annu. Rev. Biochem., 78:119.

Noguchi, N.; Suwa, J.; Narui, K.; Sasatsu, M.; Ito, T.; Hiramatsu, $K$. and Song, J. (2005): Susceptibilities to antiseptic agents and distribution of antisepticresistance genes qacA/B and $s m r$ of methicillin-resistant Staphylococcus aureus isolated in Asia during 1998 and 1999. J. Med. Microbiol., 54 (6): 557 565.

Odumosu, B.T.; Adeniyi, B.A. and Chandra, R. (2013): Analysis of integrons and associated gene cassettes in clinical isolates of multidrug resistant Pseudomonas aeruginosa from Southwest Nigeria. Ann. Clin. Microbiol. Antimicrob.,12:29.

Olivera, S.D.; Rodenbusch, C.R.; Ce, M.C.; Rocha, S.L.S. and Canal, C.W. (2003): Evaluation of selective and non-selective enrichment PCR procedures for Salmonella detection. Lett. Appl. Microbiol., 36: 217-221.

Palanisamy, S. and Bamaiyi, P.H. (2015): Isolation and antibiogram of Salmonella spp. from quails in a farm from Kelantan, Malaysia. J. Vet. Adv., 5 (12):1191-1198.

Rowe-Magnus, D.A.; Guerout, A.M. and Mazel, D. (2002): Bacterial resistance evolution by recruitment of superintegron gene cassettes. Mol. Microbiol., 43:1657-1669.

Roy, P.; Purushothaman, V.; Koteeswaran, A. and Dhillon, A.S. (2006): Isolation, characterization, and antimicrobial drug resistance pattern of Escherichia coli isolated from Japanese quail and their environment. J. Appl. Poult. Res., 15 (3): 442-446.

Saha, O.; Hoque, M.N.; Islam, O.K.; Rahaman, Md. M.; Sultana, M. and Hossain, M.A. (2020): Multidrug-resistant avian pathogenic Escherichia coli strains and association of their virulence genes in Bangladesh. Microorganisms, 8, 1135.

Salehi, M. and Ghanbarpour, R. (2010): Phenotypic and genotypic properties of Escherichia coli isolated from colisepticemic cases of Japanese quail. Trop. Ainm. Health Prod., 42: 14971504.

Santos, T.; Murakami, A.; Fanhani, J. and Oliveira, C. (2011): Production and reproduction of egg-and meat-type quails reared in different group sizes. Revista Brasileira de Ciencia Avicola, 13: 9-14.

Stepanović, S.; Vuković, D.; Veronika, H.; Bonaventura, G.D.; Djukić, S.; Cirković, 
I. and Ruzicka, F. (2007): Quantification of biofilm in microtiter plates: Overview of testing conditions and practical recommendations for assessment of biofilm production by Staphylococci. APMIS, 115 (8):891-899.

Struve, C.; Bojer, M.; Nielsen, F.M.; Hansen, D.S. and Krogfelt, K.A. (2005): Investigation of the putative virulence gene magA in a worldwide collection of 495 Klebsiella isolates: magA is restricted to the gene cluster of Klebsiella pneumoniae capsule serotype K1. J. Med. Microbiol., 54: 1111-1113.

WHO (2014): Antimicrobial resistance: Global report on surveillance. Geneva, Switzerland.

Yeh, K.; Kurup, A.; Siu, L.K.; Koh, Y.L.; Fung, C.; Lin, J.; Chen, T.; Chang, F. and Koh, T. (2007): Capsular Serotype K1 or K2, rather than magA and $r m p \mathrm{~A}$, is a major virulence determinant for Klebsiella pneumonia liver abscess in Singapore and Taiwan. J. Clin. Microbiol., 45(2): 466471.

Younis, G.; Awad, A.; El-Gamal, A. and Hosni,
R. (2016): Virulence properties and antimicrobial susceptibility profiles of Klebsiella species recovered from clinically diseased broiler chicken. Adv. Anim. Vet. Sci. 4(10):536-542.

Yousef, S.A.; Ammar, A.M. and Ahmed, D.A. (2015): Serological and molecular typing of avian pathogenic E. coli originated from outbreaks of Colibacillosis in chicken flocks. International Journal of Science and Research, 4:2082-2088.

Yusuf, M. S.; El Nabtiti, A.S. and Cui, H. (2016): Effects of NENP vs LELP diets on some laying and reproductive performance parameters of Japanese quail's hens. J. Ad. Agric. Technol., 3 (2): 132-135.

Zhao, S.; White, D.G.; Ge, B.; Ayers, S.; Friedman, S.; English, L.; Wagner, D.; Gaines, S. and Meng, J. (2001): Identification and characterization of integron-mediated antibiotic resistance among shiga toxin-producing Escherichia coli isolates. Appl. Environ. Microbiol., 67 (4): 1558-1564.

\section{عزل وتوصيف بعض أنواع البكتيريا المعوية المعزولة من النفوق المبكر لكتاكيت السمان اليابانية بمحافظة قتا ، مصر من الفر}

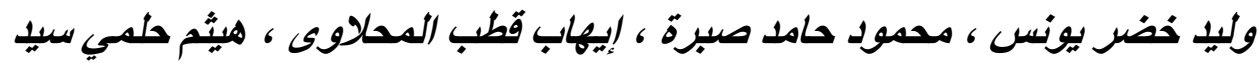

E-mail:vet_haitham@yahoo.com Assiut University web-site: www.aun.edu.eg

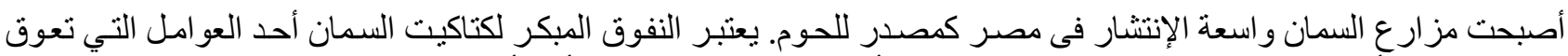

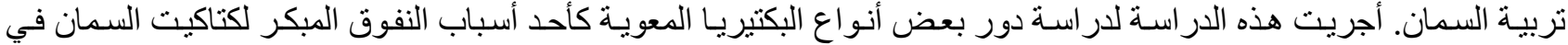

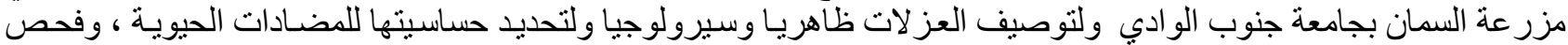

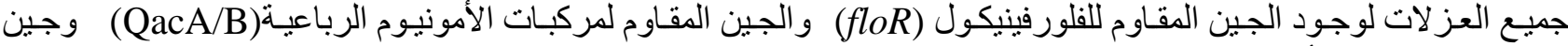

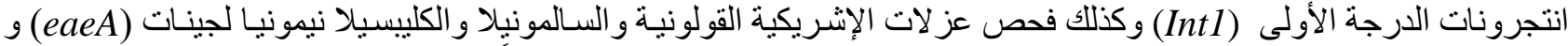

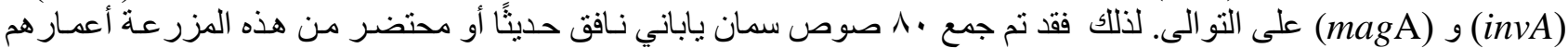

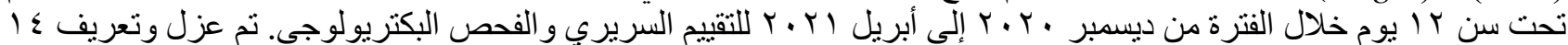

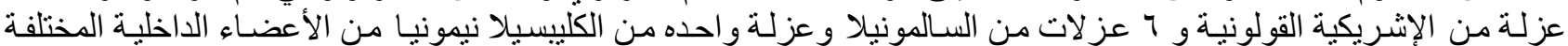

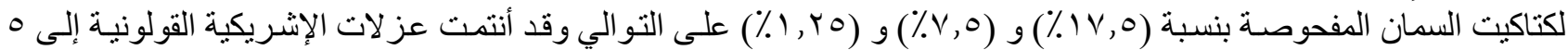
مجمو عـات مصـلية مختلفـة هـى

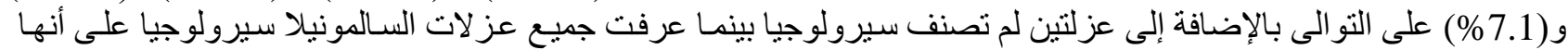

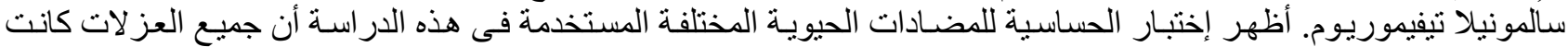

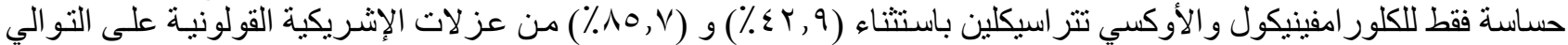

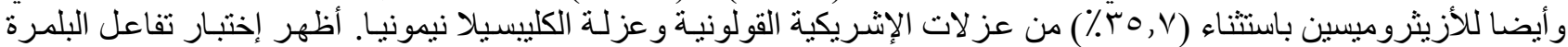

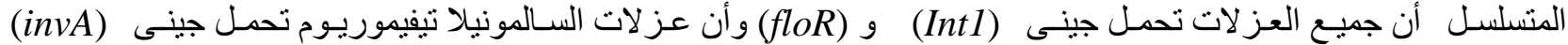

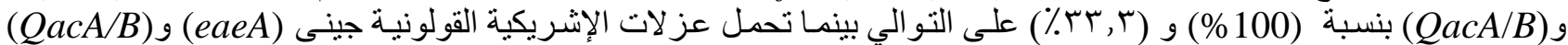

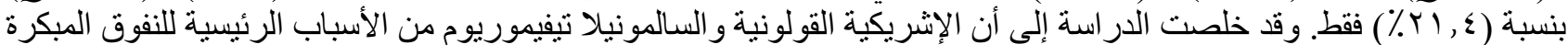

